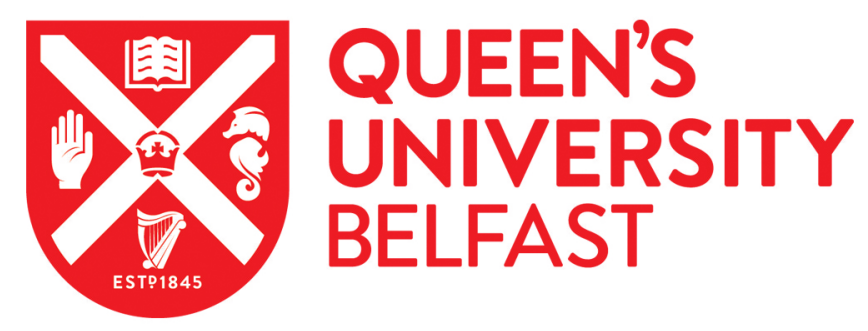

\title{
Complex Signaling Networks Controlling Dynamic Molecular Changes in Pseudomonas aeruginosa Biofilm
}

Gula, G., Dorotkiewicz-Jach, A., Korzekwa, K., Valvano, M. A., \& Drulis-Kawa, Z. (2018). Complex Signaling Networks Controlling Dynamic Molecular Changes in Pseudomonas aeruginosa Biofilm. Current medicinal chemistry. https://doi.org/10.2174/0929867325666180912110151

Published in:

Current medicinal chemistry

Document Version:

Peer reviewed version

Queen's University Belfast - Research Portal:

Link to publication record in Queen's University Belfast Research Portal

Publisher rights

Copyright 2018 Bentham Science Publishers. This work is made available online in accordance with the publisher's policies. Please refer to any applicable terms of use of the publisher.

\section{General rights}

Copyright for the publications made accessible via the Queen's University Belfast Research Portal is retained by the author(s) and / or other copyright owners and it is a condition of accessing these publications that users recognise and abide by the legal requirements associated with these rights.

Take down policy

The Research Portal is Queen's institutional repository that provides access to Queen's research output. Every effort has been made to ensure that content in the Research Portal does not infringe any person's rights, or applicable UK laws. If you discover content in the Research Portal that you believe breaches copyright or violates any law, please contact openaccess@qub.ac.uk. 


\title{
Complex Signaling Networks Controlling Dynamic Molecular Changes in
}

\section{Pseudomonas aeruginosa Biofilm}

\author{
Grzegorz Guła $^{\mathrm{a}}$, Agata Dorotkiewicz-Jach ${ }^{\mathrm{a}}$, Kamila Korzekwa ${ }^{\mathrm{b}}$, Miguel A. Valvano ${ }^{\mathrm{c}}$ and Zuzanna \\ Drulis-Kawa ${ }^{a^{*}}$
}

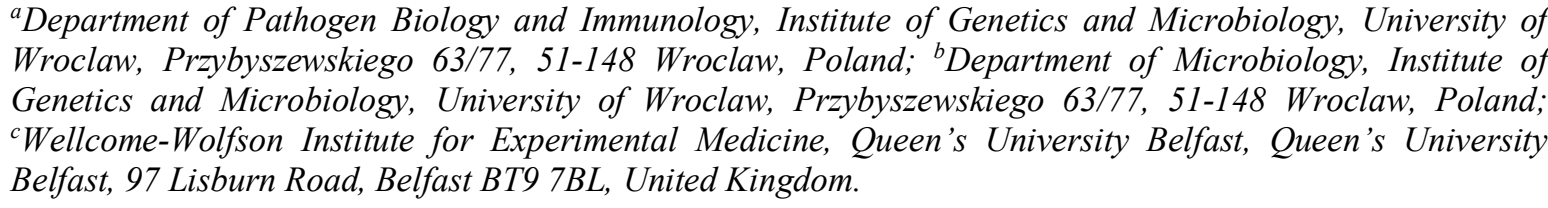

\begin{abstract}
The environment exerts strong influence on microbes. Adaptation of microbes to changing conditions is a dynamic process regulated by complex networks. Pseudomonas aeruginosa is a life-threating, versatile opportunistic and multi drug resistant pathogen that provides a model to investigate adaptation mechanisms to environmental changes. The ability of $P$. aeruginosa to form biofilms and to modify virulence in response to environmental changes are coordinated by various mechanisms including two-component systems (TCS), and secondary messengers involved in quorum sensing (QS) and c-di-GMP networks (diguanylate cyclase systems, DGC). In this review, we focus on the role of c-di-GMP during biofilm formation. We describe TCS and QS signal cascades regulated by c-di-GMP in response to changes in the external environment. We present a complex signaling network dynamically changing during the transition of $P$. aeruginosa from the free-living to sessile mode of growth.
\end{abstract}

Keywords: Pseudomonas aeruginosa, biofilm, two-component systems, diguanylate cyclase systems, quorum sensing signaling pathway.

\section{INTRODUCTION}

Pseudomonas aeruginosa belongs to the ESKAPE pathogens (Enterococcus faecium, Staphylococcus aureus, Klebsiella pneumoniae, Acinetobacter baumannii, Pseudomonas aeruginosa, Enterobacter spp.), which are major causes of nosocomial infections. These bacteria resist the action of commonly used antibacterials by multidrug resistance mechanisms (MDR) [1,2]. Low nutritional requirements and high tolerance to stress makes $P$. aeruginosa extremely dangerous both in the hospital and community environments [3]. P. aeruginosa show intrinsic resistance to penicillin G, cephalosporins (first- and second-generation), tetracyclines, aminopenicillins, macrolides, chloramphenicol, trimethoprim and sulphonamides [4-6]. Resistance depends on various mechanisms including reduced membrane permeability, efflux pump systems, and the production of enzymes inactivating or degrading antibiotics. Reduced permeability of the outer membrane due to OprD porin loss, usually results from decreased transcription of the oprD gene and/or its mutational disruption leading to the loss of a functional porin [7]. Reduced membrane permeability may be also associated to the loss of the lipopolysaccharide (LPS) Ospecific polysaccharide chain, changes in the proportion of saturated / unsaturated fatty acids, and by the addition of a 4amino-4-deoxy-L-arabinose residue to the lipid A structure $[5,8,9]$. The above mechanisms also mediate reduced susceptibility to aminoglycosides and polymyxins (B, E) [5].
Mutations in a cluster of genes encoding efflux pumps components may cause the overexpression of efflux pumps $[6,10]$. For example, the multi-drug efflux (Mex) MexABOprM, MexEF-OprN, and MexCD-OprJ pumps confer resistance to $\beta$-lactams, MexEF-OprN and MexCD-OprJ to fluoroquinolones, and MexXY-OprM to aminoglycosides $[7,11,12]$. Additionally, acquired mechanisms arising from mutation or horizontal gene transfer (HGT) can further improve $P$. aeruginosa resistance $[5,13]$. Bacteria may acquire plasmids encoding $\beta$-lactamases (ESBL, SHV, TEM, MBL types) [12], aminoglycoside-modifying enzymes (AME) [14] or AME variants capable of inactivating aminoglycosides and fluoroquinolones [15].

A large set of virulence factors enable successful colonization, invasion and propagation of $P$. aeruginos $a$ in the host. Therefore, this bacterium can cause several infections such as nosocomial pneumonia associated with an artificial ventilation, chronic obstructive pulmonary disease, chronic lung infections in cystic fibrosis (CF) patients, surface infections in wounds and in burned patients [4,11]. Infections of skin, soft tissues, and urinary tracts are more prevalent in immunocompromised patients $[5,13,16,17]$. Infections in other organs such as lymph nodes, bone marrow, myocardium, as well as in postoperative wounds are also caused by this pathogen $[18,19]$.

The virulence factors of $P$. aeruginosa can be grouped into two major categories. First, "membrane-associated" cell 
surface factors such as flagellum, fimbriae/pili, lipopolysaccharide (LPS) or alginate polysaccharide [20,21]. Second, soluble/secreted factors including pyocyanin and pyorubrin (phenazine dyes), pyoverdine and pyochelin (siderophores), alkaline protease, serine protease (LasA), zinc metalloprotease (LasB), phospholipase C, neuraminidase and various toxins (ExoA, ExoS, ExoT, ExoY, ExoU) [22,23].

Another important multifactorial virulence factor is the ability of $P$. aeruginosa to form biofilms, which allows for the colonization of various types of surfaces (catheters, intubation tubes, water pipes, taps, pumps, filters, drainage sinks and sewage grates) [24]. Biofilms play a significant role in many of the chronic infections mentioned above [24]. In CF individuals with chronic infection, $P$. aeruginosa may be present in surface-detached mucoid aggregates/biofilms and organized into free-floating mucous plugs [25].

In comparison to planktonic bacteria, sessile cells in biofilms are more resistant to surfactants, disinfectants and antibiotics [27-29]. The biofilm exopolysaccharide matrix forms a physicochemical barrier affecting the diffusion of drugs [30,31], thus restricting antibiotic access to biofilm bacterial cells. Moreover, antibiotics do not affect metabolically inactive cells ("persisters") within the biofilm.

The pathogenicity of $P$. aeruginosa is controlled by four activated in cascade quorum sensing systems (Las, Rhl, PQS and IQS systems, respectively) [30,32] and by the stationarystate sigma factor (encoded by the $r p o S$ gene). These regulatory systems have synergistic interactions, which enable $P$. aeruginosa to adapt and survive in many different host conditions and nutrients availability.

This review will discuss the main mechanisms controlling $P$. aeruginosa biofilm formation and degradation including (i) two-component systems (TCS), (ii) diguanylate cyclase systems (DGC) and (iii) quorum sensing (QS).

\section{P. AERUGINOSA BIOFILM FORMATION FACTORS AS A BIOMARKER OF DISEASE}

Biofilms are a community of surface-associated microorganisms associated embedded within a matrix of extracellular polymeric substances (EPS - extracellular polymeric substances). $P$. aeruginosa is of great interest as a model of biofilm-forming organism and research in this area has contributed to understand how biofilms are formed and the physiological states of biofilm cells. Furthermore, $P$. aeruginosa has the ability to switch from an "acute" phase to a "chronic" phase, which involves several regulatory systems and the controlled expression of different metabolic and structural factors [33,34]. We may distinguish three main phases of biofilm formation: (i) adhesion; (ii) maturation of the biofilm structure; and (iii) dispersion of the biofilm matrix with the release of planktonic cells able to colonize distant niches.

There are several "membrane-associated" cell surface factors characteristics for the adhesion process. The flagellum is required for mucin interactions and adhesion to asialoGM1 receptors on host epithelial tissue [35-37]. Moreover, fimbriae (mainly type IV and cup fimbriae) determine the adhesion [20,38,39]. A third important element is LPS, which in $P$. aeruginosa exists in two types: common polysaccharide antigen (CPA) and O-specific antigen (OSA). The CPA is built of homopolymeric trisaccharide repeating D-rhamnose units, whereas heteropolymeric OSA includes diverse monosaccharides serving for serotype classification [40]. CPA does not significantly affect the bacterial cell adherence properties [41], but the loss of OSA results in the weakening of cell adhesion to hydrophilic surfaces, simultaneously with the enhanced adhesion to hydrophobic surfaces.

Soluble/secreted compounds used for initial step of biofilm formation by $P$. aeruginosa include pyoverdine, a siderophore secreted by the PvdRT-OpmQ efflux pump [21,23,42-44], and the effectors of several secretion systems [45]. Type I and II secretion systems (T1SS and T2SS, respectively) transport effectors to the extracellular environment. T2SS secretes proteolytic and lipolytic enzymes (e.g. LasA protease, LasB elastase, collagenase, gelatinase, urokinase), as well as pyocyanin, playing a central role in the pathophysiology of $P$. aeruginosa and in the bacterial adhesion process. The general secretion pathway protein $\mathrm{D}(\mathrm{GspD})$ forms the outer membrane complex of T2SS. GspD has homologs in T3SS, type IV fimbriae biogenesis systems, and filamentous phage assembly systems [46], and GspD participates in the assembly of type IV pili, and provides for adhesion and bacterial movement.

Once adhesion is established, a maturation phase begins, in which different virulence factors are produced and secreted outside bacterial cells. The maturation begins by the synthesis of EPS matrix. Proteins, polysaccharides and eDNA are the main biofilm structural components. Pel, Psl, and alginate form the polysaccharide core of the extracellular matrix whereas, the eDNA is involved in maintaining the biofilm mushroom-like structure and responsible for horizontal gene transfer [47]. The role of alginate production in biofilm maturation remains unclear, as alginate is not involved in this process in in vitro models [48,49]. The maturation of the biofilm causes many changes in the expression of basic virulence factors in sessile cells. These changes include loss of cellular motility by expression of Fla- (flagella-free) phenotypes, protease and phospholipase $\mathrm{C}$ synthesis reduction $[30,50]$. There is also a decrease in synthesis and secretion of toxins such as exotoxins $\mathrm{A}$ and $\mathrm{S}$, and secretion of the siderophores pyochelin/pyoverdine [50]. Sessile $P$. aeruginosa cells start to produce mucus and rough LPS to better adapt to certain conditions of the biofilm microenvironment [30]. Cells living in deeper layers of biofilm and having limited access to oxygen exhibit significant slowdown of metabolic processes and cell division 
[30]. Also, sessile planktonic cells express the T6SS during biofilm maturation and switch off the T3SS, which is active at the beginning of biofilm formation [49]. The T3SS/T6SS switch reflects a complex global gene regulation delineating the transition from acute to chronic infection, as discussed below in 3.1 (Fig. 1). T6SS activity was demonstrated during biofilm maturation, where an increase in Hcp (hemolysin coregulated protein) protein expression was observed causing the biofilm-specific antibiotic resistance [51].
The last stage of the biofilm lifecycle is cell dispersion and switch to planktonic forms. At this point, the motility genes are expressed and the active cells escape from the biofilm structure. The dispersion may be caused by the depletion of nutrients, but also due to the induction of prophages and their switch from lysogenic into lytic life cycle. The consequence of cell lysis, via bacteriophages exclusion, is the release of alginate lyase able to degrade and loosening of biofilm matrix [52].

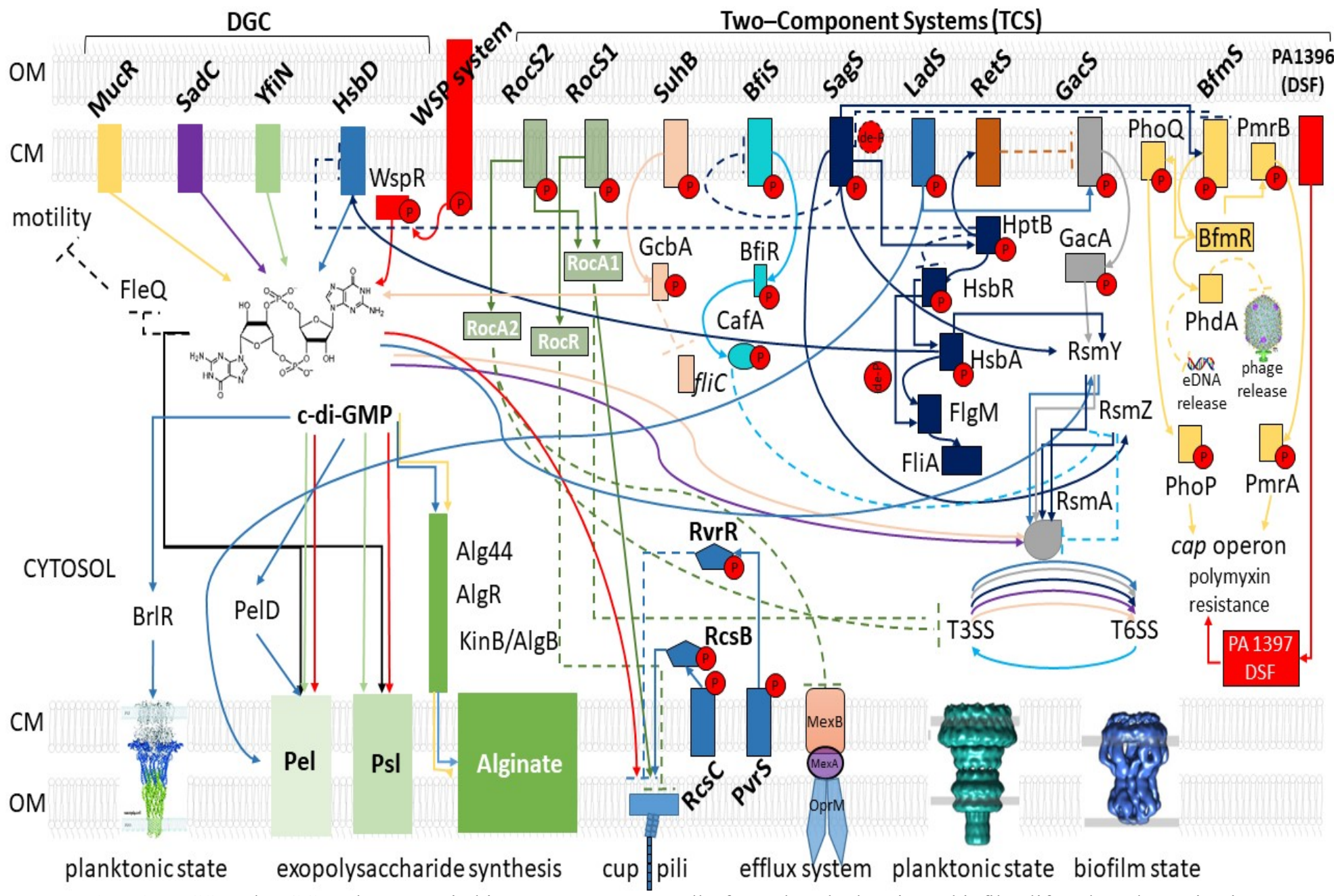

Fig. (1). TCS and DGC pathways switching $P$. aeruginosa cells from the planktonic to biofilm lifestyle. The activation pathways are crossed with solid lines, the inhibition pathways are marked with dashed lines. 


\section{DYNAMIC REGULATION OF $P$. AERUGINOSA BIOFILMS BY SIGNALING NETWORKS}

A dynamic and complex regulatory network allows $P$. aeruginosa to adapt to environmental cues. Its large genome $(\sim 6 \mathrm{Mb})$ and its plasticity helps adaptation to changing conditions, especially in the human host [53]. The control of virulence gene expression involves numerous transcriptional regulators, including regulatory RNAs and $\delta$ factors $[54,55]$. Up to $10 \%$ of $P$. aeruginosa genome content is dedicated to encode regulatory proteins $[54,56]$. There are three main groups of control mechanisms that play roles in P. aeruginosa biofilm growth: (i) two-component systems (TCS), (ii) diguanylate cyclase system (DGC) and (iii) quorum sensing (QS). A crosstalk between those systems is possible and often crucial for changing the virulence effectors at different stages of biofilm formation [55] (Fig. 1, 2). At the molecular level, the TCS regulation of signal transduction from membrane sensors takes place via phosphorelay pathways or by secondary messenger cyclic di-GMP (c-di-GMP), a key coordinator of intracellular signaling networks (Fig. 1). The intracellular level of c-di-GMP depends on membrane or cytoplasmic 3' 5' - diguanylate cyclase and phosphodiesterase (DGC/PDE) activities working independently or as part of TCS. The extracellular QS molecules (autoinducers) trigger signal transduction via TCS to induce the expression of different virulence genes by c-di-GMP signaling or phosphorylation. The signal transduction can be also induced by intracellular factors such as prophages during their switch from lysogenic to lytic life modes [57].

\subsection{P. aeruginosa two-component systems (TCSs) engaged in biofilm formation}

The TCSs are composed of histidine sensor kinases (SK) present usually in the cytoplasmic membrane and response regulators (RR) with a cytoplasmic localization (Fig. 1) [58]. The SK is characterized by the conserved kinase core while $\mathrm{RR}$ has a conserved regulatory domain. In TCS a single external stimulus or narrow range of stimuli are sensed by the periplasmic N-terminal domain of SK which dimerizes and transfer phosphoryl group to a $\mathrm{N}$-terminal conserved receiver domain of RR through phosphotransfer or phosphorelay. This event activates a downstream C-terminal effector domain of $\mathrm{RR}$ resulting in conformational changes allowing for specific binding to DNA and the modulation of gene expression. For already synthetized enzymes/proteins, the activated RR may modulate their activity by direct protein-protein interaction [58]. TCSs are "modules" that build larger control systems, and cooperate and complement each other in the case of damage events (e.g. mutation) [59]. Sixty four histidine sensor kinases and 72 response have been identified within $P$. aeruginosa genome $[56,60]$. The great variety of TCSs present in $P$. aeruginosa can be divided into specific functional groups and only the most important systems playing roles in particular steps of biofilm formation are mentioned in this review.

An important structure for biofilm attachment are the cup fimbriae encoded by the cup gene cluster [61]. P. aeruginosa has five defined fimbrial cup $(A-E)$ clusters which stay under TCS control (Roc1, Roc2 and Rcs/Pvr systems) (Fig. 1) $[62,63]$. Roc1 is composed of one SK (RocS1) and two RRs (RocA1, RocR) verified in in vivo infection model as regulating Pseudomonas virulence [64,65]. In this system RocA1 and RocR activates/inhibits cup fimbriae formation, respectively. The mechanism by which the RocS1 regulates the activity of two opposite RRs is still unknown [49]. The second system (Roc2) consists of one SK (RocS2) and one RR (RocA2) and despite of cup fimbriae production activation, it is responsible for multidrug efflux pump mexAB-oprM gene cluster repression leading to increased sensitivity to several antibiotics. Moreover, there is extensive cross-regulation between Roc1 and Roc2 [62]. The third TCS (Rcs/Pvr) that controls the expression of cup fimbriae is located on the pathogenicity island (PAPI-1) together with cup gene cluster [63]. Similarly to Roc system, RcsB activates the expression of cupD whereas PvrR has the opposite effect [63]. Type IV fimbriae are also engaged in the earlier steps of biofilm formation [66]. Type IVa fimbriae function in $P$. aeruginosa twitching motility but the regulation of the pil gene is complex and involves the sigma factor RpoN, as well as two TCSs PilR/S and FimS/AlgR TCS (Fig. 2) [67,68]. Type IVb fimbriae (Flp) are important for adhesion and produced during the late stationary growth phase in planktonic cultures. The pil gene is a part of a large gene cluster, flp-tad-crp, interacting with components of the TCS PprA/B [67]. The PprB protein induces also the cupE gene cluster regulating the assembly of CupE fimbriae, which are involved in forming the mushroomlike biofilm structures [68] (Fig. 2). The biofilm maturation is based on the production of extracellular matrix composed mainly of exopolysaccharides but also eDNA molecules and adhesins such as CdrA [69].

$P$. aeruginosa produces at least three extracellular polysaccharides (alginate, Pel, Psl) that have a role in biofilm development. The regulation of alginate synthesis is complex and includes the TCSs FimS/AlgR and $\mathrm{KinB} / \mathrm{AlgB}$, both positively regulating the alginate gene cluster expression [70] (Fig. 1,2). Additionally, studies of pel and psl gene expression have led to the discovery of a central regulatory network responsible for switching between planktonic and biofilm lifestyle, which is also important for $P$. aeruginosa transition from acute to chronic infections. The acute phenotype is usually characterized by T3SS secretion and planktonic 


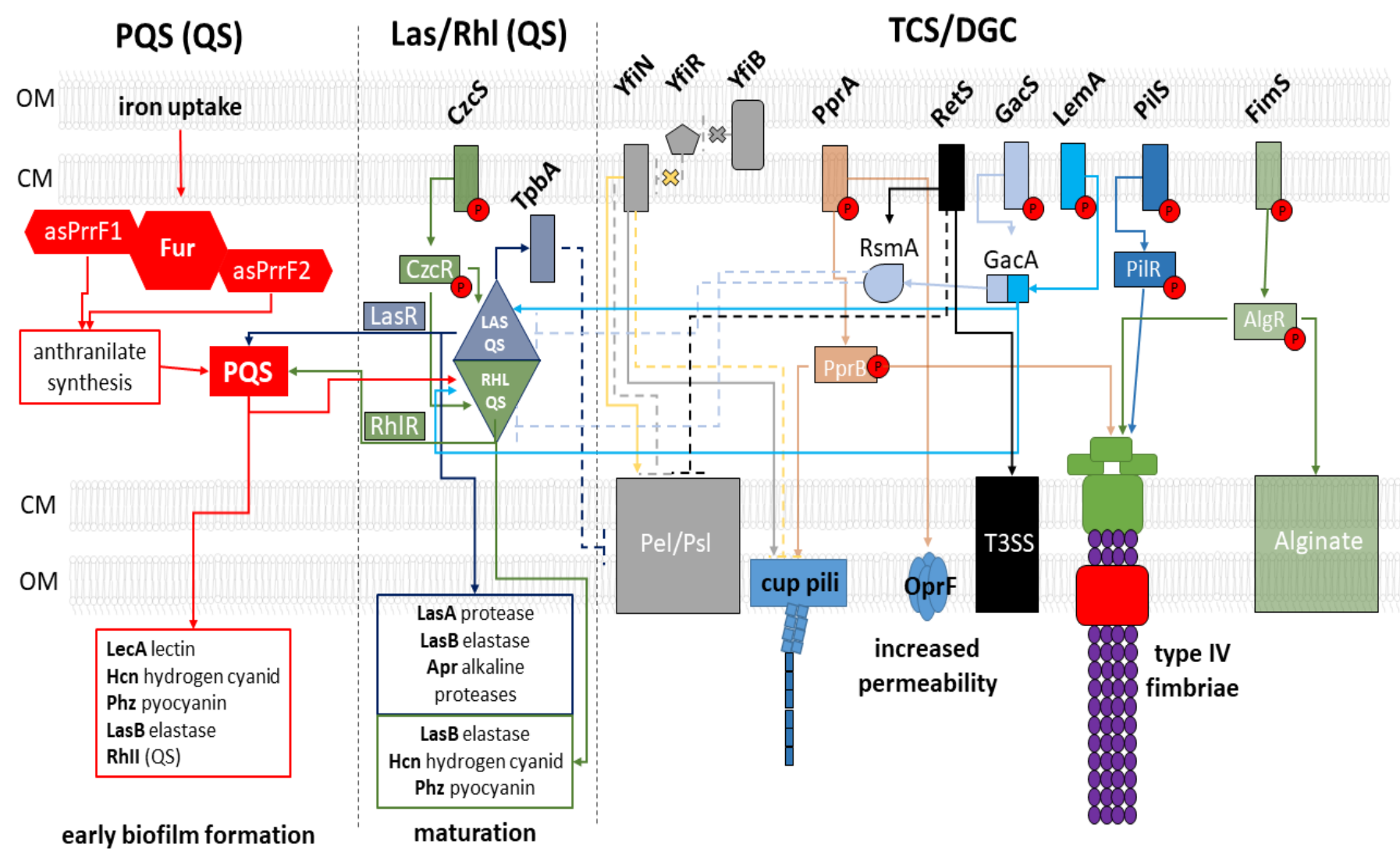

motility, whereas the chronic phenotype involves T6SS, production of pyocyanin, cyanide and biofilm formation [71].

Fig. (2). Crosstalk regulation between QS and TCS / DGC systems during P. aeruginosa biofilm formation. The activation and inhibition pathways are marked with solid and dashed lines, respectively..

The Gac system plays a major role in this transition (Fig. 1). Gac is a TCS system that consists of the transmembrane SK $(\mathrm{GacS})$ and its cognate regulator GacA. The phosphotransfer from $\mathrm{GacS}$ to GacA upregulates the expression of small regulatory RNAs (RsmZ and RsmY) that bind the RsmA. This activates the genes engaged in biofilm formation while acute virulence genes are repressed [72]. An additional SK overlapping with the Gac/Rsm cascade is the BfiS/BfiR system, which is required for the irreversible attachment of cells to particular surfaces. BfiR is a cognate receptor for BfiS, which activates the expression of CafA-RNase that reduces the level of RsmZ associated with planktonic growth (Fig. 1). The modulation of biofilm-associated genes via GacA is also possible through other sensor kinases such as LadS and RetS (membrane-bound proteins), and provides an example of a multikinase network to detect several signals and implement a coordinated response $[56,73]$. LadS positively regulates the pel cluster, while GacA, conversely, represses it. RetS acts directly by interfering with GacS activity instead of a classical phosphate group transfer [72]. GacS membrane receptor and further Gac/Rsm cascade are also interacting with HptBmediated phosporelay being an element of DGC/TCS crosstalk (see more details below in section 3.3).

\subsection{The c-di-GMP - a key signal network molecule}

The c-di-GMP molecule is composed of two GTP residues and it is synthetized by 3'5'-diguanyl cyclase (DGC) protein. Conversely, the degradation of c-di-GMP corresponds to PDE (phosphodiesterase) activity. The PDE metabolizes c-di-GMP into two products: pGpG (5-phosphoguanylyl-(3-5)guanosine) or two GMP molecules in a several-fold metabolic pathway. The interaction between DGC and PDE determines the dynamic intracellular c-di-GMP level, thus the bacterial cell adapts to environment changes $[74,75]$. The DGC protein retains its activity by the presence of an active site containing the GGDEF (glycine-glycine-aspartate-glutamatephenylalanine) motif, while the PDE has an EAL (glutamatealanine-leucine) or HD-GYP (histidine-aspartate-glycinetyrosine-proline) motifs. The structure and domain organization in DGC and PDE proteins have been well characterized and described by Jenal and Malone [76]. It is often the case that one protein has both GGDEF and EAL active sites [74]. An example of such hybrid protein having two catalytic domains (GGDEF and EAL) is the MucR protein in $P$. aeruginosa (Fig. 1). In adhesive forms of bacterial cell the MucR increases c-di-GMP level being a positive regulator of alginate synthesis. The old sessile cells are characterized by 
the active/released EAL domain of MucR participating in the nitrogen oxide/glutamate-induced biofilm dispersion process [77]. Three-way regulation of c-di-GMP in signal tracing systems have been described: (i) allosteric modifications of enzyme, (ii) interaction with transcription factor, (iii) riboswitch (interaction with srRNA) [78,79]. The c-di-GMP also participates in a post-transcriptional and posttranslational processing inside the cell. This pleiotropic effect depends on interactions with different effector proteins such as those involved in flagellum and Pel polysaccharide synthesis coordinating the switch from planktonic to biofilm mode of growth, as well as FleQ and PelD proteins or other proteins having PilZ domain [80,81] (Fig. 1). The c-di-GMP can act both globally and locally [82].

\subsection{Co-operation between DGC and TCS systems during the planktonic - sessile community transition of P. aeruginosa}

The first 3'5'- diguanyl cyclase DGC described in $P$. aeruginosa strain was the WspR protein (Fig. 1). It owes its name to a characteristic biofilm phenotype with a high content of produced exopolysaccharides (wsp - wrinkly spreader phenotype). The biofilm-rich matrix production starts with the phosphorylation of WspR activating the c-di-GMP synthesis. The c-di-GMP overproduction as a feedback results in the attachment to the WspR inhibitory domain lowering its activity $[83,84]$. Several of known DGCs are a part of the twocomponent systems (TCS). The SadC, (one of DGCs) via cdi-GMP affects the RsmA transcription factor of the Gac/Rsm system directing the cell to planktonic mode of growth. A large amount of c-di-GMP synthesized by SadC protein gives the signal for RsmA disassembly and SadC inhibition, meaning the return to biofilm formation [85,86]. $P$. aeruginosa isolates from $\mathrm{CF}$ individuals show patient'sspecific morphotype diversity [87]. One of the phenotypes, the small colony variants (SCV), is characterized by the tolerance to several classes of antibiotics, an increased synthesis of exopolysaccharides and a high level of c-di-GMP [88]. This phenotype is induced by the activity of two DGCs: $\mathrm{WspR}$ and Y fiN (also called TbpB). Small colony variants can be induced by the subinhibitory concentration of kanamycin increasing the intracellular concentration of c-di-GMP and pel and $p s l$ operons activation [89,90]. The c-di-GMP levels are sensed by several receptor proteins such as PelD or Alg44 stimulating Pel and alginate production [81,91] (Fig. 1).

Simultaneously, the increased level of c-di-GMP blocks the major FleQ motility genes activator as well as FliI enzyme leading to the inhibition of flagella biosynthesis not needed any longer for SCV or sessile mode of growth $[92,93]$. Due to the regulation based on increasing intracellular levels of c-diGMP, in parallel with transiting to the biofilm lifestyle, Pseudomonas cells activate the efflux pump-dependent on BrlR transcription factor conditioning a high tolerance to antibacterials [94,95] (Fig. 1).

The recently described HsbD (DGC) activation pathway (HsbD - $\underline{\mathbf{H}} \mathrm{ptB}$ dependent secretion and biofilm) regulates biofilm formation, chemotaxis, swimming and swarming motility. The $h p t B, h p t R$, hptA gene cluster belong to the III region of flagella synthesis. They are located adjacent to $\operatorname{rec} Q$ and region I chemotaxis genes $[75,86,96]$. The downstream $h s b D$ gene product is a DGC (HsbD) launching type IV fimbriae production which is negatively regulated by HptB. The overexpression of $h p t B$ gene is equivalent to twitching motility and biofilm formation exclusion [96,97]. In the DGC/TCS crosstalk, the HptB blocks GacS membrane receptor and further $\mathrm{Gac} / \mathrm{Rsm}$ cascade responsible for T3SS synthesis and planktonic form of cell life. As the consequence, the cells switch to sessile forms with T6SS presence [86] (Fig. 1). The main sensor interacting with HptB is SagS membrane protein belonging to TCS [71].

Simultaneously, phosphorylated $\mathrm{HptB}$ regulates c-diGMP synthesis via HsbA and HsbD (DGC) causing transition to biofilm mode of growth. So far the molecular mechanism of this process remains unclear [73].

Another newly discovered DGC/TCS co-operation module regards to GcbA as the main element of SuhB regulon. The GcbA inhibits $f l i C$ expression and activates the TCS Gac/Rsm system [98] causing T6SS production and biofilm formation. Moreover, the SuhB-dependent signal pathway results in an increased tolerance to aminoglycosides conditioned by ribosome modification [99].

\subsection{Phage-mediated cell lysis and eDNA release under the regulation of BfmSR two-component system during $P$. aeruginosa biofilm formation}

An important aspect in biofilm formation is the regulation of cell numbers inside the micro- and macro-colony and extracellular DNA (eDNA) secretion, especially in developing of mushroom-like structure. The eDNA is required for an appropriate biofilm development, integrity and architecture being a structural element, as well as it serves as a source of energy and mediates the horizontal gene transfer (HGT) [100-103]. The release of eDNA can be obtained by means of cell lysis and it is dependent on PQS (pseudomonas quinolone signal) quorum sensing activity [57]. It is suggested that eDNA excretion via PQS may be associated with the prophage presence. The prophage DMS3 residing in $P$. aeruginosa PA14 strain inhibits the biofilm formation and swarming motility. In contrast, $\mathrm{Pf} 4$ prophage in $P$. aeruginosa PAO1 is essential for a properly formed biofilm [104-107]. It is proposed that $\mathrm{BfmR}$, part of two-component $\mathrm{BfmS} / \mathrm{R}$ system, regulates the transfer from the adhesion to maturation phase of biofilm development by limiting phage-mediated lysis via newly described PhdA and thus the eDNA release [57] (Fig. 1). The BfmR controls but not eliminates cell lysis by suppression of genes involved in phage-particles assembly and phage-dependent cell lysis. Interestingly, eDNA influences the biofilm architecture only at the early maturation stage, whereas in further phase other components play important role in maintaining of biofilm structure [100]. In parallel, BfmR regulates the genes involved in DNA repair such as encoding helicases, recombinases, ligases and endonuclease, as well T2SS and T3SS and the resistance to cationic antimicrobial peptides (CAP). The accumulated eDNA is a membrane disruption signal that triggers the transcription of $b f m R$ [103]. Inactivation of $b f m R$ does not affect the expression of QS-related genes proving that BfmR 
functions independently to quorum sensing path signaling [57]. There is therefore a relationship between phagedependent cell lysis, eDNA release and two-component systems (BfmSR) that build a network of signal transduction (via c-di-GMP) affecting biofilm formation [57].

\subsection{Control of virulence and biofilm formation via TCS system recognizing the extracellular signals from diffusible signal factor (DSF) family members}

DSF (diffusible signal factor) belong to a family of molecules based on unsaturated fatty acids implicated in interspecies and inter-kingdom signaling govern to modulate the behaviour of other microorganisms [108]. DSF as signal was described in the model species Xanthomonas campestris $(\mathrm{Xcc})$ $[109,110]$. DSF family members also occur in the Stenotrophomonas, Burkholderia and Pseudomonas isolated from cystic fibrosis individuals. Several signaling factors belonging to the DSF family have been described, derivatives of cis-2- unsaturated fatty acids, each synthesized by a different type of bacteria: Xcc (cis-11-methyl-dodecenoic acid), Burkholderia cenocepacia (cis-2-dodecenoic acid) and $P$. aeruginosa (cis-2-decenoic acid) $[111,112]$. The protein DspI involved in DSF synthesis in $P$. aeruginosa is encoded by $P A 0745$ gene located in the gene cluster implicated in fatty acid synthesis $[113,114]$.

The reception of signals from DSF family members in the $X c c$ model species is carried out using a two-component $\mathrm{RpfC} / \mathrm{G}$ system, the activation of which affects cellular c-diGMP turnover. The presence of HD-GYP domain in RpfG protein causes hydrolysis of c-di-GMP into two molecules of GMP and globally activates the cell transition into planktonic mode [115]. In general, the biofilm formation is associated with high cellular level of c-di-GMP, whereas low cellular level promotes for example pilus-dependent motility [116,117]. The PA1397 Pseudomonas protein, a homologue of Xcc RpfG protein, is phosphorylated upon activation of the histidine sensor kinase PA1396 (RpfC Xcc homologue) forming TCS system. In Pseudomonas model, DSF (from Xcc) and BDSF (from Burkholderia) molecules cause the phosphorylation of DNA-binding regulator (PA1397) via the membrane sensor PA1396 affecting the expression of genes involved in polymyxin resistance and stress tolerance without the effect on the c-di-GMP level $[108,114]$.

The synthesis and dispersion of various DSFs enables microorganisms to communicate at inter-species and interkingdom levels influencing the regulation of virulence and progression of pathogens in plants, animals and humans [118].

\section{QS SYSTEMS OF P. AERUGINOSA}

Many species of bacteria produce small diffusible signaling molecules (autoinducers) which accumulate in the environment and once a threshold concentration is achieved autoinducers bind their cognate receptors activating a specific gene expression. Those mechanisms based on population density are called Quorum Sensing (QS) systems [119]. The QS system influences the expression of virulence genes, motility, activation of alternative metabolic pathways in response to stress, antibiotic resistance and switching from planktonic to biofilm mode of growth. Also the conversion from acute to chronic phenotype requires QS-dependent control of specific genes expression as more that $10 \%$ of $P$. aeruginosa genes are QS-regulated [120]. QS systems have a complex organization and crosstalk between multiple pathways and above described TCSs. Up to date four major pathways of QS dependent signaling based on three different chemical molecules have been characterized in $P$. aeruginosa. The Las and Rhl systems based on the utilization of $\mathrm{N}$-(3oxododecanoyl)-L-homoserine lactone (3-oxo-C12-HSL, OdDHL) and N-butanoyl-L-homoserine lactone (C4-HSL, BHL), respectively. Those are the classical Gram-negative autoinducers belonging to $\mathrm{N}$-acyl homoserine lactones (AHLs), molecules consisted of fatty acids linked via peptide bond to homoserine lactone moiety [121]. When a threshold concentration of AHLs is obtained in the environment they bind to specific bacterial receptors (LasR and RhlR respectively) belonging to LuxR family. OdDHL/LasR and $\mathrm{BHL} / \mathrm{RhlR}$ complexes bind to the target of conserved las/rhl boxes which act as upstream promotors activating transcriptional expression of specific genes [122]. Recent analyses showed that AHL-based systems regulate up to 353 $P$. aeruginosa genes responsible for a majority of virulence phenotypes as well as physiological processes $[123,124]$. Rhl system regulates the expression of elastase, hydrogene cyanide, phenazine, pyocyanin and rhamnolipid. The expression of genes encoding elastase, endotoxin A, alkaline protease and biofilm formation are under control of Las system [125] (Fig. 2). The involvement of $P$. aeruginosa QS systems in biofilm life cycle was firstly reported by Davis et al. as they demonstrated that lasI mutants form only flat and undifferentiated biofilm structures [126]. Therefore, Las system is mainly in use for mature biofilm development [127]. Other investigators reported that rhlI gene is involved in the formation of a mushroom-like structures and are also crucial in the dispersal stage controlling the production of rhamnolipids [128,129]. Besides above, the Rhl system controls the overproduction of alginate at the end of chronic stage [130]. Moreover, the biosurfactants and rhamnolipids contribute the formation of cavities within mature biofilm [131].

$P$. aeruginosa additionally possess several LuxR-type orphan homologues which are crucial in further regulation of AHL-based QS. RsaL is a transcriptional repressor of lasI leading to the inhibition of $r s a L$-lasI box expression therefore regulating the level of OdDHL [132]. QscR is another LuxR homologue which forms heterodimers with LasR and RhIR complexes with autoinducers preventing their binding to DNA [133]. VqsR on the other hand is a positive regulator of Las QS system while QslA is an anti-activator of LasR preventing interaction with las genes [134,135].

PQS is the third QS system used by $P$. aeruginosa, which utilize 4-qunolone compound 2-heptyl-3-hydroxy-4quinolone (PQS) as a signal molecule. PQS system controls the expression of genes encoding elastase, pyocyanin, LecA lectin and biofilm formation [125]. PQS is synthesized via the expression of $p q s A B C D$, phnAB and $p q s H$ cluster genes responsible for generating of multiple signaling molecules. 
The cognate receptor for PQS is PqsR involved in the regulation of $\mathrm{PQS}$ molecule production. PqsR is an anthranilate-coenzyme A ligase involved in the first step of PQS biosynthesis [136]. Genomic analyses showed that up to 141 genes are controlled by the PQS system [123] and it is modulated by the las system and LasR/OdDHL [137,138]. Similarly to described above BfmR (TC) system, the PQS regulates eDNA release at the early biofilm formation stage and virulence determinants production including outer membrane vesicles $[136,139,140]$.

Recently, an additional QS system containing the QscR receptor has been discovered [141]. QscR depended system (IQS) controls the production of phenazine, hydrogene cyanide, elastase and motility [141]. It integrates the response to environmental stimuli within QS network. Structurally, IQS molecules belong to 2-(2-hydroxyphenyl)-thiazole-4carbaldehyde (aeruginaldehyde) [142] and QscR is known to use OdDHL for signal activation [143]. A transcription profiling study revealed that QscR regulates the overlapping genes with Las and Rhl systems. It also separately controls a distinct subset of genes [144].

$P$. aeruginosa $\mathrm{QS}$ systems have hierarchical relationships however each of them can be activated in the response to different environmental stimuli. The highest position possesses the Las system as it influence the Rhl, PQS, and IQS pathways [124]. The Rhl system is regulated by all the other QS systems, whereas PQS is activated by Las and IQS [34].

Recently, a new signaling molecule (valdiazen) was described that is involved in virulence regulation in Burkholderia cenocepacia [145]. Valdiazen encoded by a ham gene cluster, is a cell-to-cell signal molecule controlling the production of fragin (antifungal compound). Authors have demonstrated that valdiazen might be a prototype of a new class of signal molecules utilized also by Pseudomonas genera. During the search of the ham cluster with the MultiGenBlast software, authors proved the presence of hamABCDE operon homolog in P. aeruginosa PA7. High variability in genetic organization up- and downstream of the ham clusters in Pseudomonas strains was also demonstrated as only a gene encoding GntR regulator was found in vicinity of ham cluster [145].

\section{THE CROSSTALK BETWEEN TCS/DGS AND QS SIGNALING PATHWAYS INVOLVED IN $P$. AERUGINOSA BIOFILM MODE OF GROWTH}

The knowledge of signal transduction pathways regulation in $P$. aeruginosa is often based on significant changes in bacteria phenotype introduced by mutations causing deactivation of regulators involved in signaling mechanisms. In external and host environments, bacteria utilize alternative transduction signals to facilitate adaptation to new niches. Coggan and Wolfgang hypothesize that there are several regulatory pathways leading to the attainment of a particular phenotype [119]. In particular, this applies to microbes equipped with numerous virulence factors and capable of forming multicellular communities. Adapting to external environmental factors one signal transduction regulation can be replaced by activating the alternative trait, allowing cells to return to a favorable phenotype. $P$. aeruginosa responds to intracellular signals embedded in prophage genes regulating phage lytic/lysogenic cycle decision followed by cell lysis [57]. A recent report [146] describes a novel mechanism of an "arbitrium" system allowing phages to decide whether to switch to lysogenic or lytic status, increasing the chances of survival. This phenomenon was characterized for a large group of bacilli strains. It is likely that similar communication could be observed for $P$. aeruginosa temperate phages/prophages during biofilm formation. It can be also assumed another way round that $P$. aeruginosa possesses an unknown signal transduction pathway controlling prophage induction/integration/maintenance within its genome [57].

Cellular perception of different factors is subjected to strict regulatory processes at various steps of biofilm formation. In general, signaling based on two-component systems, c-di-GMP or protein phosphorylation of different proteins in biofilm formation have also been characterized. There are interdependencies, but also switching between signal transduction pathways depending on the type of external cue and cell functioning in the biofilm. In addition, several crosstalk mechanisms are described in this review.

One of the most important regulators of biofilm formation is c-di-GMP. This molecule participates in signal transduction from various TCS systems. Its pleiotropy was observed for exclusion of motility genes connected with simultaneous synthesis of essential matrix polysaccharides via Alg44, AlgR or $\mathrm{AlgU}[147,148]$. The last two regulators participate in the synthesis of alginate, but also inhibit the synthesis of RhlR autoinducer $P$. aeruginosa quorum sensing [119]. This is one of the first described crosstalk that occurs between the QS and TCS systems via c-di-GMP, where the switch from acute to chronic virulence is controlled. The high concentration of cdi-GMP causes cell transition into sessile mode of growth [75].

The transition from an acute to chronic style of life in $P$. aeruginosa depends on the synthesis of key PcrV and Hcp-1 proteins controlling T3SS and T6SS expression, respectively [119]. The regulation of PcrV and Hcp-1 synthesis occurs by activation of one of the earliest discovered TCS system with a key DGC WspR. WpsR overexpression leads to significant exopolysaccharide and biofilm production via a high c-diGMP concentration [149]. Similar effect is observed after DGC YfiN activation. In this case, also a reduction in PcrV synthesis and increased production of Hcp-1 was observed, indicating that there are many alternative pathways for cell transitions in the chronic trait. Probably there are also interactions between these pathways, triggered in case of failure of one signal transduction pathway [119]. The opposite regulation occurs through the activity of TbpA (PDE) controlled by the synthesis of Las QS molecules [150]. Another CzcR/S two component system additionally activates the Las/Rhl QS signals [151] (Fig. 2).

The aforementioned pathways play a crucial role in determining of $P$. aeruginosa lifestyle by detecting variation of environmental conditions and controlling global phenotypic changes [119]. The potential signal for Gac/Rsm, RetS and LadS cascade is likely responding to carbon 
availability in the environment [72,73]. Another important agent influencing the signal transduction is oxygen [152]. The intracellular cue (phage) is controlled by $\mathrm{BfmR} / \mathrm{S}$ inhibition, with the main component PhdA protein protecting cell from lysis and e-DNA release [57]. BfmR/S controlled by RetS/SagS/Gac/Rsm upregulates the activity of PhoPQ and PmrAB increasing cell resistance to cationic antibiotics. Simultaneously, the RetS/SagS/Gac/Rsm regulons affect the synthesis of LasR, RhlR, the main regulators of QS system autoinducers synthesis [153,154]. Another PQS system is activated by Fur (TCS) regulon. Low concentration of ferric ions induce the synthesis of anthranilate (precursor of PQS autoinducers) controlled by Fur (Fig. 2) [55]. The main key element conditioning crosstalk between different TCS/DGC and QS pathways is the c-di-GMP molecule. The physiological relevance of external signals, in the context of a complex environmental or host niche, has yet to be determined and represents an important and future direction for the field. Current progress in this area is hampered by the lack of suitable model systems and because many of the cues mentioned are likely to have pleiotropic effects. An obvious limitation of in vitro experiments, even when using epithelial cell models, is that they may not reflect what happens in the clinical setting. Further, most of the work on signaling pathways was carried out using one or two laboratory $P$. aeruginosa strains (PAO1 and PA14). Thus, phenotypic variations in laboratory isolates may not completely reflect the $P$. aeruginosa population behavior during clinical infection.

\section{CONFLICT OF INTEREST}

The authors confirm that this article content has no conflicts of interest.

\section{ACKNOWLEDGEMENTS}

This work was supported by project UMO2015/18/M/NZ6/00413 from the National Science Centre, Poland.

\section{REFERENCES}

[1] Boucher, H. W.; Talbot, G. H.; Bradley, J. S.; Edwards, J. E.; Gilbert, D.; Rice, L. B.; Scheld, M.; Spellberg, B.; Bartlett, J. Bad Bugs, No Drugs: No ESKAPE! An update from the Infectious Diseases Society of America. Clin. Infect. Dis., 2009, 48 (1), 112 .

[2] Hancock, R. E. W.; Speert, D. P. Antibiotic resistance in Pseudomonas aeruginosa: mechanisms and impact on treatment. Drug Resist. Updat., 2000, 3 (4), 247-255.

[3] Livermore, D. M. Radiolabelling of penicillin-binding proteins (PBPs) in intact Pseudomonas aeruginosa cells: Consequences of $\beta$-lactamase activity by pbp-5. J. Antimicrob. Chemother., 1987, 19 (6), 733-742.

[4] Nikaido, H. Molecular basis of bacterial outer membrane permeability revisited. Microbiol. Mol. Biol. Rev., 2003, 67 (4), 593-656

[5] Livermore, D. M. Multiple mechanisms of antimicrobial resistance in Pseudomonas aeruginosa: Our worst nightmare?
Clin. Infect. Dis., 2002, 34 (5), 634-640.

[6] Strateva, T.; Yordanov, D. Pseudomonas aeruginosa - A phenomenon of bacterial resistance. J. Med. Microbiol., 2009, 58 (9), 1133-1148.

[7] Lister, P. D.; Wolter, D. J.; Hanson, N. D. Antibacterial-resistant Pseudomonas aeruginosa: clinical impact and complex regulation of chromosomally encoded resistance mechanisms. Clin. Microbiol. Rev., 2009, 22 (4), 582-610.

[8] Lee, J.-Y.; Na, I. Y.; Park, Y. K.; Ko, K. S. Genomic variations between colistin-susceptible and -resistant Pseudomonas aeruginosa clinical isolates and their effects on colistin resistance. J. Antimicrob. Chemother, 2014, 69 (5), 1248-1256.

[9] Olaitan, A. O.; Morand, S.; Rolain, J.-M. Mechanisms of polymyxin resistance: acquired and intrinsic resistance in bacteria. Front. Microbiol., 2014, 5 (NOV), 643.

[10] El Amin, N.; Giske, C. G.; Jalal, S.; Keijser, B.; Kronvall, G.; Wretlind, B. Carbapenem resistance mechanisms in Pseudomonas aeruginosa: Alterations of porin OprD and efflux proteins do not fully explain resistance patterns observed in clinical isolates. APMIS, 2005, 113 (3), 187-196.

[11] Li, X.-Z.; Plésiat, P.; Nikaido, H. The challenge of effluxmediated antibiotic resistance in Gram-negative bacteria. Clin. Microbiol. Rev., 2015, 28 (2), 337-418.

[12] Potron, A.; Poirel, L.; Nordmann, P. Emerging broad-spectrum resistance in Pseudomonas aeruginosa and Acinetobacter baumannii: Mechanisms and epidemiology. Int. J. Antimicrob. Agents, 2015, 45 (6), 568-585.

[13] Empel, J.; Filczak, K.; Mrówka, A.; Hryniewicz, W.; Livermore, D. M.; Gniadkowski, M. Outbreak of Pseudomonas aeruginosa infections with PER-1 extended-spectrum $\beta$-lactamase in Warsaw, Poland: Further evidence for an international clonal complex. $J$. Clin. Microbiol., 2007, 45 (9), 2829-2834.

[14] Poole, K. Aminoglycoside resistance in Pseudomonas aeruginosa. Antimicrob. Agents Chemother., 2005, 49 (2), 479-487.

[15] Kos, V. N.; Déraspe, M.; McLaughlin, R. E.; Whiteaker, J. D.; Roy, P. H.; Alm, R. A.; Corbeil, J.; Gardner, H. The resistome of Pseudomonas aeruginosa in relationship to phenotypic susceptibility. Antimicrob. Agents Chemother., 2015, 59 (1), 427436.

[16] Wolter, D. J.; Hanson, N. D.; Lister, P. D. AmpC and OprD are not involved in the mechanism of imipenem hypersusceptibility among Pseudomonas aeruginosa isolates overexpressing the mexCD-oprJ efflux pump. Antimicrob. Agents Chemother., 2005, 49 (11), 4763-4766.

[17] Henriques Normark, B.; Normark, S. Evolution and spread of antibiotic resistance. J. Intern. Med., 2002, 252 (2), 91-106.

[18] Trafny, E. A. Powstawanie biofilmu Pseudomonas aeruginosa i jego znaczenie w patogenezie zakazen przewleklych. Postep. Mikrobiol., 2000, 39 (1), 55-71.

[19] Wolcott, R.; Costerton, J. W.; Raoult, D.; Cutler, S. J. The polymicrobial nature of biofilm infection. Clin. Microbiol. Infect., 2013, 19 (2), 107-112.

[20] Kipnis, E.; Sawa, T.; Wiener-Kronish, J. Targeting mechanisms of Pseudomonas aeruginosa pathogenesis. Medecine et Maladies Infectieuses. 2006, pp 78-91. 
[21] Van Delden, C.; Iglewski, B. H. Cell-to-cell signaling and Pseudomonas aeruginosa infections. Emerg. Infect. Dis., 1998, 4 (4), 551-560.

[22] Lee, V. T.; Smith, R. S.; Tümmler, B.; Lory, S. Activities of Pseudomonas aeruginosa effectors secreted by the type III secretion system in vitro and during infection. Infect. Immun., 2005, 73 (3), 1695-1705.

[23] Visca, P.; Imperi, F.; Lamont, I. L. Pyoverdine siderophores: from biogenesis to biosignificance. Trends Microbiol., 2007, 15 (1), 22-30.

[24] Bixler, G. D.; Bhushan, B. Biofouling: lessons from nature. Philos. Trans. R. Soc. A Math. Phys. Eng. Sci., 2012, 370 (1967), 2381-2417.

[25] Roberts, A. E. L.; Kragh, K. N.; Bjarnsholt, T.; Diggle, S. P. The limitations of in vitro experimentation in understanding biofilms and chronic infection. J. Mol. Biol., 2015, 427 (23), 3646-3661.

[26] Bjarnsholt, T.; Jensen, P. Ø.; Fiandaca, M. J.; Pedersen, J.; Hansen, C. R.; Andersen, C. B.; Pressler, T.; Givskov, M.; Høiby, N. Pseudomonas aeruginosa biofilms in the respiratory tract of cystic fibrosis patients. Pediatr. Pulmonol., 2009, 44 (6), 547558.

[27] Kirisits, M. J.; Prost, L.; Starkey, M.; Parsek, M. R. Characterization of colony morphology variants isolated from Pseudomonas aeruginosa biofilms. Appl. Environ. Microbiol., 2005, 71 (8), 4809-4821.

[28] Drenkard, E. Antimicrobial resistance of Pseudomonas aeruginosa biofilms. Microbes Infect., 2003, 5 (13), 1213-1219.

[29] Gillis, R. J.; White, K. G.; Choi, K.-H.; Wagner, V. E.; Schweizer, H. P.; Iglewski, B. H. Molecular basis of azithromycin-resistant Pseudomonas aeruginosa biofilms. Antimicrob. Agents Chemother., 2005, 49 (9), 3858-3867.

[30] Prakash, B.; Veeregowda, B. M.; Krishnappa, G. Biofilms: A survival strategy of bacteria. Curr. Sci., 2003, 85 (9), 1299-1307.

[31] Spoering, A. L.; Lewis, K. Biofilms and planktonic cells of Pseudomonas aeruginosa have similar resistance to killing by antimicrobials. J. Bacteriol., 2001, 183 (23), 6746-6751.

[32] Lee, J.; Zhang, L. The hierarchy quorum sensing network in Pseudomonas aeruginosa. Protein Cell, 2014, 6 (1), 26-41.

[33] Alhazmi, A. Pseudomonas aeruginosa - Pathogenesis and Pathogenic Mechanisms. Int. J. Biol., 2015, 7 (2).

[34] Moradali, M. F.; Ghods, S.; Rehm, B. H. A. Pseudomonas aeruginosa Lifestyle: A Paradigm for Adaptation, Survival, and Persistence. Front. Cell. Infect. Microbiol., 2017, 7 (39).

[35] Sauer, K.; Camper, A. K.; Ehrlich, G. D.; Costerton, J. W.; Davies, D. G. Pseudomonas aeruginosa displays multiple phenotypes during development as a biofilm. J. Bacteriol., 2002, 184 (4), 1140-1154.

[36] Adamo, R.; Sokol, S.; Soong, G.; Gomez, M. I.; Prince, A. Pseudomonas aeruginosa flagella activate airway epithelial cells through asialoGM1 and toll-like receptor 2 as well as toll-like receptor 5. Am. J. Respir. Cell Mol. Biol., 2004, 30 (5), 627-634.

[37] Arora, S. K.; Ritchings, B. W.; Almira, E. C.; Lory, S.; Ramphal, $\mathrm{R}$. The Pseudomonas aeruginosa flagellar cap protein, FliD, is responsible for mucin adhesion. Infect. Immun., 1998, 66 (3), $1000-1007$.
[38] Mattick, J. S. Type IV pili and twitching motility. Annu. Rev. Microbiol., 2002, 56 (1), 289-314.

[39] Semmler, A. B. T.; Whitchurch, C. B.; Mattick, J. S. A reexamination of twitching motility in Pseudomonas aeruginosa. Microbiology, 1999, 145 (10), 2863-2873.

[40] Rocchetta, H. L.; Burrows, L. L.; Lam, J. S. Genetics of O-antigen biosynthesis in Pseudomonas aeruginosa. Microbiol. Mol. Biol. Rev., 1999, 63 (3), 523-553.

[41] Makin, S. A.; Beveridge, T. J. The influence of A-band and Bband lipopolysaccharide on the surface characteristics and adhesion of Pseudomonas aeruginosa to surfaces. Microbiology, 1996, 142 (2), 299-307.

[42] Hall, S.; McDermott, C.; Anoopkumar-Dukie, S.; McFarland, A. J.; Forbes, A.; Perkins, A. V; Davey, A. K.; Chess-Williams, R.; Kiefel, M. J.; ... Grant, G. D. Cellular effects of pyocyanin, a secreted virulence factor of Pseudomonas aeruginosa. Toxins (Basel)., 2016, 8 (8), 1-14.

[43] Schalk, I. J.; Guillon, L. Pyoverdine biosynthesis and secretion in Pseudomonas aeruginosa: Implications for metal homeostasis. Environ. Microbiol., 2013, 15 (6), 1661-1673.

[44] Musk, D. J.; Banko, D. A.; Hergenrother, P. J. Iron salts perturb biofilm formation and disrupt existing biofilms of Pseudomonas aeruginosa. Chem. Biol., 2005, 12 (7), 789-796.

[45] Lee, V. T.; Schneewind, O. Protein secretion and the pathogenesis of bacterial infections. Genes Dev., 2001, 15 (14), 1725-1752.

[46] Korotkov, K. V.; Sandkvist, M.; Hol, W. G. J. The type II secretion system: biogenesis, molecular architecture and mechanism. Nat. Rev. Microbiol., 2012, 10 (5), 336-351.

[47] Flemming, H. C.; Wingender, J. The biofilm matrix. Nat. Rev. Microbiol., 2010, 8 (9), 623-633.

[48] Jain, S.; Ohman, D. E. Role of an alginate lyase for alginate transport in mucoid Pseudomonas aeruginosa. Infect. Immun., 2005, 73 (10), 6429-6436.

[49] Mikkelsen, H.; Sivaneson, M.; Filloux, A. Key two-component regulatory systems that control biofilm formation in Pseudomonas aeruginosa. Environ. Microbiol., 2011, 13 (7), 1666-1681.

[50] Xu, K. D.; Stewart, P. S.; Xia, F.; Huang, C. T.; McFeters, G. A. Spatial physiological heterogeneity in Pseudomonas aeruginosa biofilm is determined by oxygen availability. Appl. Environ. Microbiol., 1998, 64 (10), 4035-4039.

[51] Zhang, L.; Hinz, A. J.; Nadeau, J. P.; Mah, T. F. Pseudomonas aeruginosa tss C1 links type VI secretion and biofilm-specific antibiotic resistance. J. Bacteriol., 2011, 193 (19), 5510-5513. Alkawash, M. A.; Soothill, J. S.; Schiller, N. L. Alginate lyase enhances antibiotic killing of mucoid Pseudomonas aeruginosa in biofilms. APMIS, 2006, 114 (2), 131-138.

Lambert, P. A. Mechanisms of antibiotic resistance in Pseudomonas aeruginosa. J. R. Soc. Med., 2002, 95 Suppl 4 (Suppl 41), 22-26.

Stover, C. K.; Pham, X. Q.; Erwin, A. L.; Mizoguchi, S. D.; Warrener, P.; Hickey, M. J.; Brinkman, F. S. L.; Hufnagle, W. O.; Kowalik, D. J.; ... Olson, M. V. Complete genome sequence of Pseudomonas aeruginosa PAO1, an opportunistic pathogen. Nature, 2000, 406 (6799), 959-964.

[55] Balasubramanian, D.; Schneper, L.; Kumari, H.; Mathee, K. A 
dynamic and intricate regulatory network determines

Pseudomonas aeruginosa virulence. Nucleic Acids Res., 2013, 41 (1), 1-20.

[56] Francis, V. I.; Stevenson, E. C.; Porter, S. L. Two-component systems required for virulence in Pseudomonas aeruginosa. FEMS Microbiol. Lett., 2017, 364 (11).

[57] Petrova, O. E.; Schurr, J. R.; Schurr, M. J.; Sauer, K. The novel Pseudomonas aeruginosa two-component regulator $\mathrm{BfmR}$ controls bacteriophage-mediated lysis and DNA release during biofilm development through PhdA. Mol. Microbiol., 2011, 81 (3), 767-783.

[58] Stock, A. M.; Robinson, V. L.; Goudreau, P. N. Two-component signal transduction. Annu. Rev. Biochem., 2000, 69, 183-215.

[59] Willett, J. W.; Crosson, S. Atypical modes of bacterial histidine kinase signaling. Mol. Microbiol., 2017, 103 (2), 197-202.

[60] Rodrigue, A.; Quentin, Y.; Lazdunski, A.; Méjean, V.; Foglino, M. Two-component systems in Pseudomonas aeruginosa: why so many? Trends Microbiol., 2000, 8 (11), 498-504.

[61] Vallet, I.; Olson, J. W.; Lory, S.; Lazdunski, A.; Filloux, A. The chaperone/usher pathways of Pseudomonas aeruginosa: identification of fimbrial gene clusters (cup) and their involvement in biofilm formation. Proc. Natl. Acad. Sci. U. S. A., 2001, 98 (12), 6911-6916.

[62] Sivaneson, M.; Mikkelsen, H.; Ventre, I.; Bordi, C.; Filloux, A. Two-component regulatory systems in Pseudomonas aeruginosa: An intricate network mediating fimbrial and efflux pump gene expression. Mol. Microbiol., 2011, 79 (5), 1353-1366.

[63] Mikkelsen, H.; Ball, G.; Giraud, C.; Filloux, A. Expression of Pseudomonas aeruginosa cupD fimbrial genes is antagonistically controlled by RcsB and the EAL-containing PvrR response regulators. PLoS One, 2009, 4 (6), e6018.

[64] Kulasekara, H. D.; Ventre, I.; Kulasekara, B. R.; Lazdunski, A.; Filloux, A.; Lory, S. A novel two-component system controls the expression of Pseudomonas aeruginosa fimbrial cup genes. Mol. Microbiol., 2005, 55 (2), 368-380.

[65] Gallagher, L. A.; Manoil, C. Pseudomonas aeruginosa PAO1 kills Caenorhabditis elegans by cyanide poisoning. J. Bacteriol., 2001, 183 (21), 6207-6214.

[66] O’Toole, G. A.; Kolter, R. Flagellar and twitching motility are necessary for Pseudomonas aeruginosa biofilm development. Mol. Microbiol., 1998, 30 (2), 295-304.

[67] Hobbs, M.; Collie, E. S. R.; Free, P. D.; Livingston, S. P.; Mattick, J. S. PilS and PilR, a two-component transcriptional regulatory system controlling expression of type 4 fimbriae in Pseudomonas aeruginosa. Mol. Microbiol., 1993, 7 (5), 669-682.

[68] Whitchurch, C. B.; Alm, R. A.; Mattick, J. S. The alginate regulator AlgR and an associated sensor FimS are required for twitching motility in Pseudomonas aeruginosa. Proc. Natl. Acad. Sci., 1996, 93 (18), 9839-9843.

[69] Borlee, B. R.; Goldman, A. D.; Murakami, K.; Samudrala, R.; Wozniak, D. J.; Parsek, M. R. Pseudomonas aeruginosa uses a cyclic-di-GMP-regulated adhesin to reinforce the biofilm extracellular matrix. Mol. Microbiol., 2010, 75 (4), 827-842.

[70] Ma, S.; Wozniak, D. J.; Ohman, D. E. Identification of the histidine protein kinase KinB in Pseudomonas aeruginosa and its phosphorylation of the alginate regulator AlgB. J. Biol. Chem., 1997, 272 (29), 17952-17960.

Moscoso, J. A.; Mikkelsen, H.; Heeb, S.; Williams, P.; Filloux, A. The Pseudomonas aeruginosa sensor RetS switches Type III and Type VI secretion via c-di-GMP signalling. Environ. Microbiol., 2011, 13 (12), 3128-3138.

[72] Goodman, A. L.; Merighi, M.; Hyodo, M.; Ventre, I.; Filloux, A.; Lory, S. Direct interaction between sensor kinase proteins mediates acute and chronic disease phenotypes in a bacterial pathogen. Genes Dev., 2009, 23 (2), 249-259.

[73] Ventre, I.; Goodman, A. L.; Vallet-Gely, I.; Vasseur, P.; Soscia, C.; Molin, S.; Bleves, S.; Lazdunski, A.; Lory, S.; Filloux, A. Multiple sensors control reciprocal expression of Pseudomonas aeruginosa regulatory RNA and virulence genes. Proc. Natl. Acad. Sci. U. S. A., 2006, 103 (1), 171-176.

[74] Valentini, M.; Filloux, A. Biofilms and Cyclic di-GMP (c-diGMP) signaling: Lessons from Pseudomonas aeruginosa and other bacteria. J. Biol. Chem., 2016, 291 (24), 12547-12555.

[75] Petrova, O. E.; Sauer, K. SagS contributes to the motile-sessile switch and acts in concert with BfiSR to enable Pseudomonas aeruginosa biofilm formation. J. Bacteriol., 2011, 193 (23), 6614 6628.

[76] Jenal, U.; Malone, J. Mechanisms of cyclic-di-GMP signaling in bacteria. Annu. Rev. Genet., 2006, 40 (1), 385-407.

[77] Hay, I. D.; Remminghorst, U.; Rehm, B. H. A. MucR, a novel membrane-associated regulator of alginate biosynthesis in Pseudomonas aeruginosa. Appl. Environ. Microbiol., 2009, 75 (4), 1110-1120

[78] Chou, S. H.; Galperin, M. Y. Diversity of cyclic di-GMP-binding proteins and mechanisms. J. Bacteriol., 2016, 198 (1), 32-46.

[79] Hengge, R. Cyclic-di-GMP reaches out into the bacterial RNA world. Sci. Signal., 2010, 3 (149), pe44.

[80] Li, Z.; Chen, J. H.; Hao, Y.; Nair, S. K. Structures of the PelD cyclic diguanylate effector involved in pellicle formation in Pseudomonas aeruginosa PAO1. J. Biol. Chem., 2012, 287 (36), 30191-30204.

[81] Whitney, J. C.; Colvin, K. M.; Marmont, L. S.; Robinson, H.; Parsek, M. R.; Howell, P. L. Structure of the cytoplasmic region of PelD, a degenerate diguanylate cyclase receptor that regulates exopolysaccharide production in Pseudomonas aeruginosa. $J$. Biol. Chem., 2012, 287 (28), 23582-23593.

[82] Romling, U.; Galperin, M. Y.; Gomelsky, M. Cyclic di-GMP: the First 25 Years of a Universal Bacterial Second Messenger.

Microbiol. Mol. Biol. Rev., 2013, 77 (1), 1-52.

[83] Hengge, R. Principles of c-di-GMP signalling in bacteria. Nat. Rev. Microbiol., 2009, 7 (4), 263-273.

[84] Huangyutitham, V.; Güvener, Z. T.; Harwood, C. S. Subcellular clustering of the phosphorylated WspR response regulator protein stimulates its diguanylate cyclase activity. MBio, 2013, 4 (3), e00242-13.

[85] O 'Toole, G. A. How Pseudomonas aeruginosa regulates surface behaviors at surfaces, these bacteria either form biofilms or swarm, a regulated behavior with important consequences for pathogenesis. Microbe, 2008, 3 (2), 65-71.

[86] Moscoso, J. A.; Jaeger, T.; Valentini, M.; Hui, K.; Jenal, U.; 
Filloux, A. The diguanylate cyclase $\mathrm{SadC}$ is a central player in Gac/Rsm-mediated biofilm formation in Pseudomonas aeruginosa. J. Bacteriol., 2014, 196 (23), 4081-4088.

[87] Mowat, E.; Paterson, S.; Fothergill, J. L.; Wright, E. A.; Ledson, M. J.; Walshaw, M. J.; Brockhurst, M. A.; Winstanley, C. Pseudomonas aeruginosa population diversity and turnover in cystic fibrosis chronic infections. Am. J. Respir. Crit. Care Med., 2011, 183 (12), 1674-1679.

[88] Malone, J. G.; Jaeger, T.; Spangler, C.; Ritz, D.; Spang, A.; Arrieumerlou, C.; Kaever, V.; Landmann, R.; Jenal, U. YfiBNR mediates cyclic di-GMP dependent small colony variant formation and persistence in Pseudomonas aeruginosa. PLoS Pathog., 2010, 6 (3), e1000804

[89] Drenkard, E.; Ausubel, F. M. Pseudomonas biofilm formation and antibiotic resistance are linked to phenotypic variation. Nature, 2002, 416 (6882), 740-743.

[90] Hickman, J. W.; Tifrea, D. F.; Harwood, C. S. A chemosensory system that regulates biofilm formation through modulation of cyclic diguanylate levels. Proc. Natl. Acad. Sci., 2005, 102 (40), 14422-14427.

[91] Merighi, M.; Lee, V. T.; Hyodo, M.; Hayakawa, Y.; Lory, S. The second messenger bis-(3'-5')-cyclic-GMP and its PilZ domaincontaining receptor $\mathrm{Alg} 44$ are required for alginate biosynthesis in Pseudomonas aeruginosa. Mol. Microbiol., 2007, 65 (4), 876895.

[92] Baraquet, C.; Harwood, C. S. Cyclic diguanosine monophosphate represses bacterial flagella synthesis by interacting with the Walker A motif of the enhancer-binding protein FleQ. Proc. Natl. Acad. Sci. U. S. A., 2013, 110 (46), 18478-18483.

[93] Ramelot, T. A.; Yee, A.; Cort, J. R.; Semesi, A.; Arrowsmith, C. H.; Kennedy, M. A. NMR structure and binding studies confirm that PA4608 from Pseudomonas aeruginosa is a PilZ domain and a c-di-GMP binding protein. Proteins Struct. Funct. Bioinforma., 2006, 66 (2), 266-271.

[94] Chambers, J. R.; Liao, J.; Schurr, M. J.; Sauer, K. BrlR from Pseudomonas aeruginosa is a c-di-GMP-responsive transcription factor. Mol. Microbiol., 2014, 92 (3), 471-487.

[95] Imada, K.; Minamino, T.; Tahara, A.; Namba, K. Structural similarity between the flagellar type III ATPase FliI and F1ATPase subunits. Proc. Natl. Acad. Sci., 2007, 104 (2), 485-490.

[96] Lin, C. T.; Huang, Y. J.; Chu, P. H.; Hsu, J. L.; Huang, C. H.; Peng, H. L. Identification of an HptB-mediated multi-step phosphorelay in Pseudomonas aeruginosa PAO1. Res. Microbiol., 2006, 157 (2), 169-175.

[97] Mern, D. S.; Ha, S. W.; Khodaverdi, V.; Gliese, N.; Gorisch, H. A complex regulatory network controls aerobic ethanol oxidation in Pseudomonas aeruginosa: indication of four levels of sensor kinases and response regulators. Microbiology, 2010, 156 (5), $1505-1516$.

[98] Li, K.; Yang, G.; Debru, A. B.; Li, P.; Zong, L.; Li, P.; Xu, T.; Wu, W.; Jin, S.; Bao, Q. SuhB regulates the motile-sessile switch in Pseudomonas aeruginosa through the Gac/Rsm pathway and cdi-GMP signaling. Front. Microbiol., 2017, 8, 1045.

[99] Shi, J.; Jin, Y.; Bian, T.; Li, K.; Sun, Z.; Cheng, Z.; Jin, S.; Wu, $\mathrm{W}$. SuhB is a novel ribosome associated protein that regulates expression of MexXY by modulating ribosome stalling in Pseudomonas aeruginosa. Mol. Microbiol., 2015, 98 (2), 370383.

[100] Whitchurch, C. B.; Tolker-Nielsen, T.; Ragas, P. C.; Mattick, J. S. Extracellular DNA required for bacterial biofilm formation. Science, 2002, 295 (5559), 1487.

[101] Allesen-Holm, M.; Barken, K. B.; Yang, L.; Klausen, M.; Webb, J. S.; Kjelleberg, S.; Molin, S.; Givskov, M.; Tolker-Nielsen, T. A characterization of DNA release in Pseudomonas aeruginosa cultures and biofilms. Mol. Microbiol., 2006, 59 (4), 1114-1128.

[102] Barken, K. B.; Pamp, S. J.; Yang, L.; Gjermansen, M.; Bertrand, J. J.; Klausen, M.; Givskov, M.; Whitchurch, C. B.; Engel, J. N.; Tolker-Nielsen, T. Roles of type IV pili, flagellum-mediated motility and extracellular DNA in the formation of mature multicellular structures in Pseudomonas aeruginosa biofilms. Environ. Microbiol., 2008, 10 (9), 2331-2343.

[103] Mulcahy, H.; Charron-Mazenod, L.; Lewenza, S. Extracellular DNA chelates cations and induces antibiotic resistance in Pseudomonas aeruginosa biofilms. PLoS Pathog., 2008, 4 (11), e1000213.

[104] Rice, S. A.; Tan, C. H.; Mikkelsen, P. J.; Kung, V.; Woo, J.; Tay, M.; Hauser, A.; McDougald, D.; Webb, J. S.; Kjelleberg, S. The biofilm life cycle and virulence of Pseudomonas aeruginosa are dependent on a filamentous prophage. ISME J., 2009, 3 (3), 271282 .

[105] Zegans, M. E.; Wagner, J. C.; Cady, K. C.; Murphy, D. M.; Hammond, J. H.; O’Toole, G. A. Interaction between bacteriophage DMS3 and host CRISPR region inhibits group behaviors of Pseudomonas aeruginosa. J. Bacteriol., 2009, 91 (1), 210-219.

[106] Webb, J. S.; Thompson, L. S.; James, S.; Charlton, T.; TolkerNielsen, T.; Koch, B.; Givskov, M.; Kjelleberg, S. Cell death in Pseudomonas aeruginosa biofilm development. J. Bacteriol., 2003, 185 (15), 4585-4592.

[107] Webb, J. S.; Lau, M.; Kjelleberg, S. Bacteriophage and phenotypic variation in Pseudomonas aeruginosa biofilm development. J. Bacteriol., 2004, 186 (23), 8066-8073.

[108] Ryan, R. P.; Fouhy, Y.; Garcia, B. F.; Watt, S. A.; Niehaus, K.; Yang, L.; Tolker-Nielsen, T.; Dow, J. M. Interspecies signalling via the Stenotrophomonas maltophilia diffusible signal factor influences biofilm formation and polymyxin tolerance in Pseudomonas aeruginosa. Mol. Microbiol., 2008, 68 (1), 75-86.

[109] Tang, J.-L.; Liu, Y.-N.; Barber, C. E.; Dow, J. M.; Wootton, J. C.; Daniels, M. J. Genetic and molecular analysis of a cluster of rpf genes involved in positive regulation of synthesis of extracellular enzymes and polysaccharide in Xanthomonas campestris pathovar campestris. MGG Mol. Gen. Genet., 1991, 226 (3), 409-417.

[110] Barber, C. E.; Tang, J. L.; Feng, J. X.; Pan, M. Q.; Wilson, T. J. G.; Slater, H.; Dow, J. M.; Williams, P.; Daniels, M. J. A novel regulatory system required for pathogenicity of Xanthomonas campestris is mediated by a small diffusible signal molecule. Mol. Microbiol., 1997, 24 (3), 555-566.

[111] Boon, C.; Deng, Y.; Wang, L.-H.; He, Y.; Xu, J.-L.; Fan, Y.; Pan, S. Q.; Zhang, L.-H. A novel DSF-like signal from Burkholderia cenocepacia interferes with Candida albicans morphological 
transition. ISME J., 2008, 2 (1), 27-36.

[112] Davies, D. G.; Marques, C. N. H. A fatty acid messenger is responsible for inducing dispersion in microbial biofilms. $J$. Bacteriol., 2009, 191 (5), 1393-1403.

[113] Slater, H.; Alvarez-Morales, A.; Barber, C. E.; Daniels, M. J.; Dow, J. M. A two-component system involving an HD-GYP domain protein links cell-cell signalling to pathogenicity gene expression in Xanthomonas campestris. Mol. Microbiol., 2002, 38 (5), 986-1003.

[114] Amari, D. T.; Marques, C. N. H.; Davies, D. G. The putative enoyl-coenzyme A hydratase DspI is required for production of the Pseudomonas aeruginosa biofilm dispersion autoinducer cis2-decenoic acid. J. Bacteriol., 2013, 195 (20), 4600-4610.

[115] Cohen, D.; Mechold, U.; Nevenzal, H.; Yarmiyhu, Y.; Randall, T. E.; Bay, D. C.; Rich, J. D.; Parsek, M. R.; Kaever, V.; ... Banin, E. Oligoribonuclease is a central feature of cyclic diguanylate signaling in Pseudomonas aeruginosa. Proc. Natl. Acad. Sci. U. S. A., 2015, 112 (36), 11359-11364.

[116] An, S.; Ryan, R. P. Combating chronic bacterial infections by manipulating cyclic nucleotide-regulated biofilm formation. Future Med. Chem., 2016, 8 (9), 949-961.

[117] Ryan, R. P. Cyclic di-GMP signalling and the regulation of bacterial virulence. Microbiology, 2013, 159 (7), 1286-1297.

[118] Ryan, R. P.; An, S.; Allan, J. H.; McCarthy, Y.; Dow, J. M. The DSF family of cell-cell signals: An expanding class of bacterial virulence regulators. PLOS Pathog., 2015, 11 (7), e1004986.

[119] Coggan, K. A.; Wolfgang, M. C. Global regulatory pathways and cross-talk control Pseudomonas aeruginosa environmental lifestyle and virulence phenotype. Curr. Issues Mol. Biol., 2012, 14 (2), 47-70.

[120] Venturi, V. Regulation of quorum sensing in Pseudomonas. FEMS Microbiol. Rev., 2006, 30 (2), 274-291.

[121] Fuqua, W. C.; Winans, S. C.; Greenberg, E. P. Quorum sensing in bacteria: The LuxR-LuxI family of cell density- responsive transcriptional regulators. J. Bacteriol., 1994, 176 (2), 269-275.

[122] Schuster, M.; Greenberg, E. P. Early activation of quorum sensing in Pseudomonas aeruginosa reveals the architecture of a complex regulon. BMC Genomics, 2007, 8, 287.

[123] Schuster, M.; Lostroh, C. P.; Ogi, T.; Greenberg, E. P. Identification, timing, and signal specificity of Pseudomonas aeruginosa quorum-controlled genes: A transcriptome analysis. $J$. Bacteriol., 2003, 185 (7), 2066-2079.

[124] Schuster, M.; Greenberg, E. P. A network of networks: Quorumsensing gene regulation in Pseudomonas aeruginosa. Int. J. Med. Microbiol., 2006, 296 (2-3), 73-81.

[125] Wilder, C. N.; Diggle, S. P.; Schuster, M. Cooperation and cheating in Pseudomonas aeruginosa: the roles of the Las, Rhl and Pqs quorum-sensing systems. ISME J., 2011, 5, 1332-1343.

[126] Davies, D. G.; Parsek, M. R.; Pearson, J. P.; Iglewski, B. H.; Costerton, J. W.; Greenberg, E. P. The involvement of cell-to-cell signals in the development of a bacterial biofilm. Science (80-. )., 1998, 280 (5361), 295-298.

[127] Lee, K.; Yoon, S. S. Pseudomonas aeruginosa biofilm, a programmed bacterial life for fitness. J. Microbiol. Biotechnol., 2017, 27 (6), 1053-1064.
[128] Juhas, M.; Eberl, L.; Tümmler, B. Quorum sensing: The power of cooperation in the world of Pseudomonas. Environmental Microbiology. 2005, pp 459-471.

[129] Patriquin, G. M.; Banin, E.; Gilmour, C.; Tuchman, R.; Greenberg, E. P.; Poole, K. Influence of quorum sensing and iron on twitching motility and biofilm formation in Pseudomonas aeruginosa. J. Bacteriol., 2008, 190 (2), 662-671.

[130] Bjarnsholt, T.; Jensen, P. Ø.; Jakobsen, T. H.; Phipps, R.; Nielsen, A. K.; Rybtke, M. T.; Tolker-Nielsen, T.; Givskov, M.; Høiby, N.; ... Scandinavian Cystic Fibrosis Study Consortium. Quorum sensing and virulence of Pseudomonas aeruginosa during lung infection of cystic fibrosis patients. PLoS One, 2010, 5 (4), e10115.

[131] Dusane, D. H.; Zinjarde, S. S.; Venugopalan, V. P.; McLean, R. J. C.; Weber, M. M.; Rahman, P. K. S. M. Quorum sensing: Implications on rhamnolipid biosurfactant production. Biotechnol. Genet. Eng. Rev., 2010, 27 (1), 159-184.

[132] Rampioni, G.; Schuster, M.; Greenberg, E. P.; Bertani, I.; Grasso, M.; Venturi, V.; Zennaro, E.; Leoni, L. RsaL provides quorum sensing homeostasis and functions as a global regulator of gene expression in Pseudomonas aeruginosa. Mol. Microbiol., 2007, 66 (6), 1557-1565.

[133] Ledgham, F.; Ventre, I.; Soscia, C.; Foglino, M.; Sturgis, J. N.; Lazdunski, A. Interactions of the quorum sensing regulator QscR: Interaction with itself and the other regulators of Pseudomonas aeruginosa LasR and RhlR. Mol. Microbiol., 2003, 48 (1), 199210 .

[134] Li, L. L.; Malone, J. E.; Iglewski, B. H. Regulation of the Pseudomonas aeruginosa quorum-sensing regulator VqsR. $J$. Bacteriol., 2007, 189 (12), 4367-4374.

[135] Seet, Q.; Zhang, L. H. Anti-activator QslA defines the quorum sensing threshold and response in Pseudomonas aeruginosa. Mol. Microbiol., 2011, 80 (4), 951-965.

[136] Gallagher, L. A.; McKnight, S. L.; Kuznetsova, M. S.; Pesci, E. C.; Manoil, C. Functions required for extracellular quinolone signaling by Pseudomonas aeruginosa. J. Bacteriol., 2002, 184 (23), 6472-6480.

[137] Schertzer, J. W.; Boulette, M. L.; Whiteley, M. More than a signal: non-signaling properties of quorum sensing molecules. Trends Microbiol., 2009, 17 (5), 189-195.

[138] Camilli, A.; Bassler, B. L. Bacterial small-molecule signaling pathways. Science (80-. )., 2006, 311 (5764), 1113-1116.

[139] Yang, L.; Nilsson, M.; Gjermansen, M.; Givskov, M.; TolkerNielsen, T. Pyoverdine and PQS mediated subpopulation interactions involved in Pseudomonas aeruginosa biofilm formation. Mol. Microbiol., 2009, 74 (6), 1380-1392.

[140] Pamp, S. J.; Tolker-Nielsen, T. Multiple roles of biosurfactants in structural biofilm development by Pseudomonas aeruginosa. J. Bacteriol., 2007, 189 (6), 2531-2539.

[141] Chugani, S. A.; Whiteley, M.; Lee, K. M.; D’Argenio, D.; Manoil, C.; Greenberg, E. P. QscR, a modulator of quorum-sensing signal synthesis and virulence in Pseudomonas aeruginosa. Proc. Natl. Acad. Sci., 2001, 98 (5), 2752-2757.

[142] Lee, J.; Wu, J.; Deng, Y.; Wang, J.; Wang, C.; Wang, J.; Chang, C.; Dong, Y.; Williams, P.; Zhang, L. H. A cell-cell 
communication signal integrates quorum sensing and stress response. Nat. Chem. Biol., 2013, 9 (5), 339-343.

[143] Lee, D. G.; Urbach, J. M.; Wu, G.; Liberati, N. T.; Feinbaum, R. L.; Miyata, S.; Diggins, L. T.; He, J.; Saucier, M.; ... Ausubel, F. M. Genomic analysis reveals that Pseudomonas aeruginosa virulence is combinatorial. Genome Biol., 2006, 7 (10), r90.

[144] Lequette, Y.; Lee, J. H.; Ledgham, F.; Lazdunski, A.; Greenberg, E. P. A distinct QscR regulon in the Pseudomonas aeruginosa quorum-sensing circuit. J. Bacteriol., 2006, 188 (9), 3365-3370.

[145] Jenul, C.; Sieber, S.; Daeppen, C.; Mathew, A.; Lardi, M.; Pessi, G.; Hoepfner, D.; Neuburger, M.; Linden, A.; ... Eberl, L. Biosynthesis of fragin is controlled by a novel quorum sensing signal. Nat. Commun., 2018, 9 (1), 1297.

[146] Erez, Z.; Steinberger-Levy, I.; Shamir, M.; Doron, S.; StokarAvihail, A.; Peleg, Y.; Melamed, S.; Leavitt, A.; Savidor, A.; .. Sorek, R. Communication between viruses guides lysis-lysogeny decisions. Nature, 2017, 541 (7638), 488-493.

[147] Dasgupta, N.; Ferrell, E. P.; Kanack, K. J.; West, S. E. H.; Ramphal, R. FleQ, the gene encoding the major flagellar regulator of Pseudomonas aeruginosa, is sigma70 dependent and is downregulated by $\mathrm{Vfr}$, a homolog of Escherichia coli cyclic AMP receptor protein. J. Bacteriol., 2002, 184 (19), 5240-5250.

[148] Martin, D. W.; Schurr, M. J.; Yu, H.; Deretic, V. Analysis of promoters controlled by the putative sigma factor $\mathrm{AlgU}$ regulating conversion to mucoidy in Pseudomonas aeruginosa: Relationship to sigma $\mathrm{E}$ and stress response. J. Bacteriol., 1994, 176 (21), 6688-6696.

[149] Malone, J. G.; Williams, R.; Christen, M.; Jenal, U.; Spiers, A. J.; Rainey, P. B. The structure-function relationship of WspR, a Pseudomonas fluorescens response regulator with a GGDEF output domain. Microbiology, 2007, 153 (4), 980-994.

[150] Ueda, A.; Wood, T. K. Connecting quorum sensing, c-di-GMP, pel polysaccharide, and biofilm formation in Pseudomonas aeruginosa through tyrosine phosphatase TpbA (PA3885). PLoS Pathog., 2009, 5 (6), e1000483.

[151] Dieppois, G.; Ducret, V.; Caille, O.; Perron, K. The transcriptional regulator CzcR modulates antibiotic resistance and quorum sensing in Pseudomonas aeruginosa. PLoS One, 2012, 7 (5), 126.

[152] O’Callaghan, J.; Reen, F. J.; Adams, C.; O’Gara, F. Low oxygen induces the type III secretion system in Pseudomonas aeruginosa via modulation of the small RNAs $r s m Z$ and $r s m Y$. Microbiology, 2011, 157 (12), 3417-3428.

[153] Williams, P.; Cámara, M. Quorum sensing and environmental adaptation in Pseudomonas aeruginosa: a tale of regulatory networks and multifunctional signal molecules. Curr. Opin. Microbiol., 2009, 12 (2), 182-191.

[154] Gupta, K.; Marques, C. N. H.; Petrova, O. E.; Sauer, K. Antimicrobial tolerance of pseudomonas aeruginosa biofilms is activated during an early developmental stage and requires the two-component hybrid sagS. J. Bacteriol., 2013, 195 (21), 49754987.

\footnotetext{
*Address correspondence to this author at the Department of Pathogen Biology and Immunology, Institute of Genetics and Microbiology, Wroclaw, Przybyszewskiego 63-77, 51-148 Wroclaw, Poland; Tel/Fax: +48 7137562 90; E-mails: zuzanna.drulis-kawa@uwr.edu.pl
} 